\title{
De menselijk motor : the human engine
}

Citation for published version (APA):

van Loon, L. J. C. (2011). De menselijk motor : the human engine. Maastricht University. https://doi.org/10.26481/spe.20111110ll

Document status and date:

Published: 10/11/2011

DOI:

10.26481/spe.20111110॥

Document Version:

Publisher's PDF, also known as Version of record

\section{Please check the document version of this publication:}

- A submitted manuscript is the version of the article upon submission and before peer-review. There can be important differences between the submitted version and the official published version of record.

People interested in the research are advised to contact the author for the final version of the publication, or visit the DOI to the publisher's website.

- The final author version and the galley proof are versions of the publication after peer review.

- The final published version features the final layout of the paper including the volume, issue and page numbers.

Link to publication

\footnotetext{
General rights rights.

- You may freely distribute the URL identifying the publication in the public portal. please follow below link for the End User Agreement:

www.umlib.nl/taverne-license

Take down policy

If you believe that this document breaches copyright please contact us at:

repository@maastrichtuniversity.nl

providing details and we will investigate your claim.
}

Copyright and moral rights for the publications made accessible in the public portal are retained by the authors and/or other copyright owners and it is a condition of accessing publications that users recognise and abide by the legal requirements associated with these

- Users may download and print one copy of any publication from the public portal for the purpose of private study or research.

- You may not further distribute the material or use it for any profit-making activity or commercial gain

If the publication is distributed under the terms of Article $25 \mathrm{fa}$ of the Dutch Copyright Act, indicated by the "Taverne" license above, 


\section{De menselijke motor}

\section{The human engine}

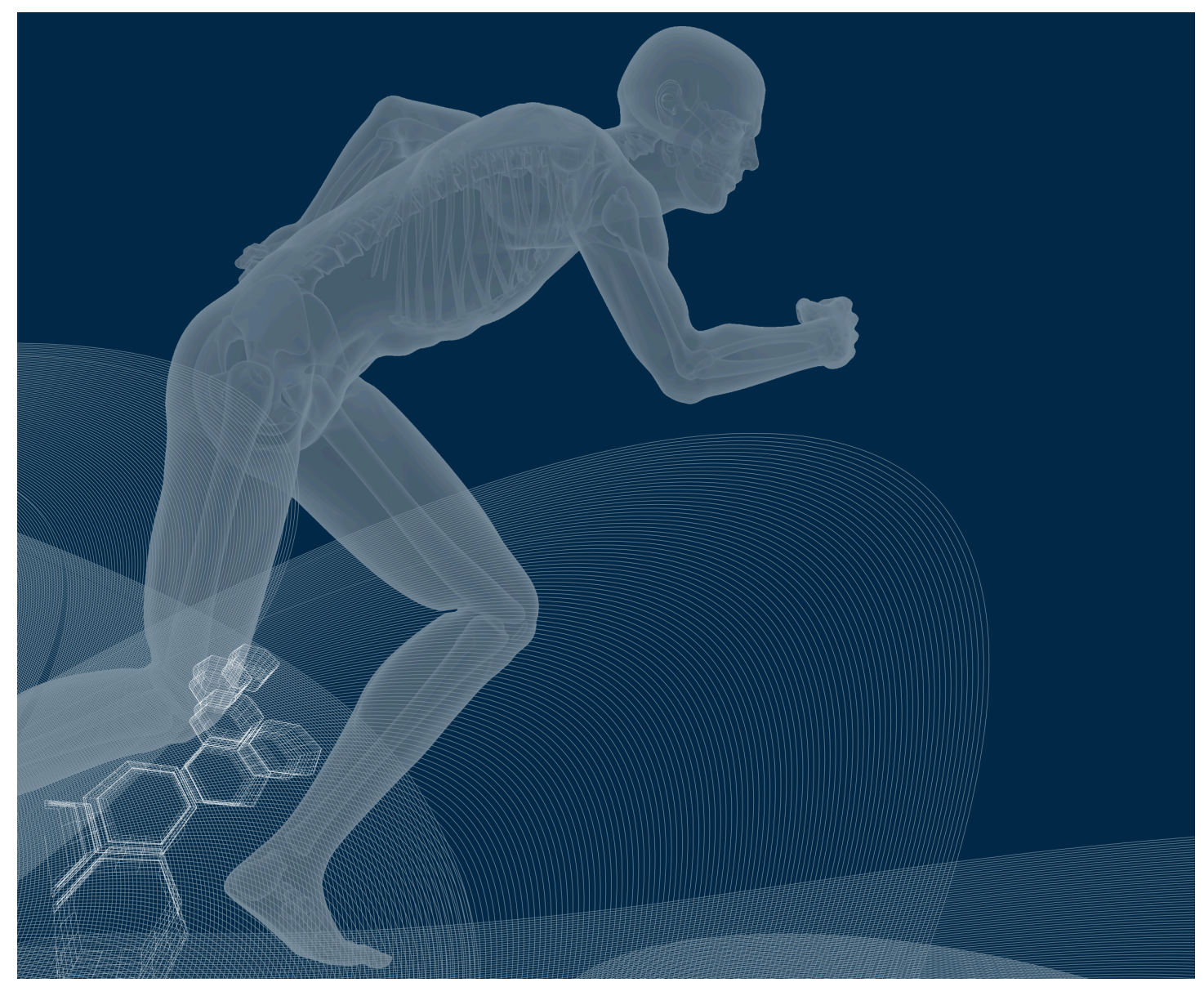

\section{Rede}

uitgesproken bij de aanvaarding van het ambt van bijzonder hoogleraar fysiologie van inspanning met bijzondere aandacht voor de rol van voeding aan de Faculty of Health, Medicine and Life Sciences

op donderdag 10 november 2011 door

Prof. dr. Luc van Loon 


\section{Voorwoord}

Ons bewegingsapparaat is een ongelofelijk complexe machine. Tot op heden is geen enkele machine in staat gebleken de mogelijkheden van de menselijke motor te evenaren. In mijn inaugurele rede probeer ik mijn fascinatie voor de menselijke skeletspier toe te lichten aan de hand van het onderzoek waar mijn onderzoeksgroep zich al ruim 12 jaar op toelegt. In tegenstelling tot de conventionele verbrandingsmotor is de menselijke motor in staat om zelf de juiste brandstof te kiezen die nodig is om optimaal te kunnen presteren. Behalve de keuze van de meest geschikte brandstof wordt ook de meest gunstige locatie gekozen waar die brandstof vandaan wordt gehaald. Kennis op het gebied van de regulatie van de brandstofselectie van de skeletspier is de basis geweest voor de ontwikkeling van sportvoeding. Inmiddels is wetenschappelijk onderzoek op dit gebied uitgegroeid tot een volwassen tak van sport waarin we onderzoeken hoe we de menselijke motor kunnen voorzien van de juiste hoeveelheid substraten om deze zo goed mogelijk te kunnen laten functioneren.

Wanneer we onze menselijke motor echter structureel voorzien van teveel brandstof kunnen er op termijn vervelende technische mankementen ontstaan. Onze huidige leefstijl wordt gekenmerkt door een (te) hoge energie inname en (te) weinig fysieke activiteit, hetgeen leidt tot overgewicht en obesitas. Lichaamsvet hoopt zich daarbij niet alleen op in ons vetweefsel maar ook in organen als de lever, alvleesklier, hart, en spieren. Dit leidt tot insuline resistentie en type 2 diabetes, met een sterk verhoogde bloed glucose concentratie tot gevolg. Skeletspierweefsel is in staat om veel glucose uit het bloed op te nemen en daarmee de bloed glucose homeostase te verbeteren. Een dagelijkse portie fysieke inspanning van 30-60 minuten is al voldoende om de prevalentie van een excessief hoge bloedglucose spiegel te halveren. Fysieke inspanning vormt daarmee een uiterst effectief medicijn bij de preventie en behandeling van type 2 diabetes, met bijwerkingen die positief zijn voor de gezondheid.

Behalve het zelf kunnen kiezen van de meest geschikte brandstof, heeft de menselijke motor een uniek vermogen zich aan te passen aan de belasting die het opgelegd krijgt. De plasticiteit van de skeletspier biedt een uitzonderlijk vermogen tot adaptatie, welke mensen in staat stelt tot het lopen van een marathon of het tillen van gewichten zwaarder dan het eigen lichaamsgewicht. Kortom een motor die zijn capaciteit kan afstemmen op de soort prestaties die ervan verwacht worden. Structurele veranderingen aan de menselijke motor treden echter ook op wanneer het bewegingsapparaat niet of nauwelijks wordt gebruikt. Een 
dergelijke deconditionering zal het vermogen om inspanning te kunnen leveren sterk doen verminderen, wat leidt tot een beperkte functionele capaciteit en een groter risico op het ontwikkelen van chronisch metabole ziekten. Dit zien we vooral terug bij veroudering waarbij verlies optreedt van spiermassa en kracht, ook wel sarcopenie genoemd.

Met het klimmen van de leeftijd verliezen we gaandeweg een aanzienlijke hoeveelheid spiermassa. Waar op jonge leeftijd nog ruim 50\% van ons lichaamsgewicht uit spierweefsel bestaat, neemt dit gedurende ons leven af tot zo'n $25 \%$. Dit gebeurt vaak zonder dan we dit merken en zonder daling van het lichaamsgewicht. Dit spiermassa verlies is ook niet altijd aan de buitenkant zichtbaar. In het lichaam zien we echter een sterk verminderde hoeveelheid spierweefsel, met specifieke atrofie van de type 2 spiervezels. De verouderde motor kan minder kracht leveren en is sneller vermoeid, en kan op termijn ernstige beperkingen ervaren in het dagelijks functioneren. Alhoewel grotendeels onduidelijk is waarom we onze spiermassa geleidelijk verliezen, zijn er sterke aanwijzingen dat oudere spieren minder gevoeling zijn voor de belangrijkste anabole stimuli, zoals voeding en inspanning. Het verlies van spiermassa en functioneel vermogen met het klimmen van de leeftijd wordt veelal beschouwd als iets dat onvermijdbaar is. Niets is echter minder waar. Wanneer men voor het nuttigen van een maaltijd voldoende fysiek actief is blijkt veel meer van het eiwit in onze voeding omgezet te worden in spierweefsel. Dus zelfs op hoge leeftijd kan middels het verhogen van de dagelijke hoeveelheid fysieke activiteit en het toepassen van specifieke krachttraining een enorme toename in spiermassa, kracht, en functioneel vermogen bereikt worden. Het verlies van spiermassa met de leeftijd is dan ook voor een belangrijk deel toe te schrijven aan een minder actieve levensstijl en dit is gelukkig tot op hoge leeftijd nog omkeerbaar. We kunnen daarmee dan ook gerust stellen dat gezond ouder worden topsport is.

Ik heb gezegd.

Luc

Prof. dr. Luc van Loon

Hoogleraar Fysiologie van Inspanning. 